\title{
Development of a Tribological Test Programme Based on Press Hardening Simulations
}

\author{
Liang Deng ${ }^{1} \cdot$ Sergej Mozgovoy $^{1} \cdot$ Jens Hardell $^{1} \cdot$ Braham Prakash $^{1} \cdot$ \\ Mats Oldenburg ${ }^{1}$
}

Received: 8 December 2016/ Accepted: 8 February 2017/Published online: 21 February 2017

(C) The Author(s) 2017. This article is published with open access at Springerlink.com

\begin{abstract}
Press hardening is widely utilized to form ultrahigh-strength steels characterized by a high strength-toweight ratio for automotive components. Press hardening processes include heating boron-manganese steels to austenite phase, forming the steels at a high temperature, and cooling the formed blanks until the martensite phase is reached. However, press hardening processes lead to severe contact conditions between the blank and the tools including contact pressure, relative sliding, and high temperatures, which result in tool wear and increased maintenance cost. The contact conditions that occur in the stamping tool are difficult to study on site. Additionally, simplified tests, such as pin on disc and ball on disc, are insufficient to reproduce press hardening conditions in laboratory environments. The aim of this study includes developing a tribological test with press hardening conditions in which tool steel pins continuously slide on fresh and hot boron-manganese steel strips. The test programme mimics press hardening conditions with respect to sliding distance, sliding velocity, contact pressure, and surface temperature that were studied based on finite element (FE) simulations of a press hardening experiment. Furthermore, a FE simulation of the tribological test is established and it provides contact temperature in the pin tip with a high accuracy. A tribological test is used to study friction and mass loss with variational pressures and velocities that represented typically variational contact conditions in the press hardening. The tribological test is also used to obtain correlations between the tribological behaviours and
\end{abstract}

\footnotetext{
Liang Deng

liang.deng@1tu.se

Luleå University of Technology, 97187 Luleå, Sweden
}

process parameters in press hardening including pressure and sliding velocity.

Keywords Contact conditions · FE simulation ·

Tribological test · Tribological behaviours

\section{Introduction}

In comparison with cold forming operations, press hardening processes include heating boron-manganese steel sheets to an austenite phase, forming steel sheets at high temperatures, and quenching formed parts until the martensite phase is reached. However, harsh working conditions including high temperatures, cyclic loading, and sliding processes, result in severe wear in the stamping tool. This in addition to shortening the service life of the stamping tool also increases rejection of produced parts. Thus, it is necessary to possess a deep understanding of tribological behaviours that occur in the stamping tool. However, this is restricted by the difficulty of on-site measurements and the lack of a simplified test with a high reproducibility of press hardening conditions.

Most terminology standards define friction as the resistance to sliding a solid body over or along another body and wear as the progressive removal of material from a surface in contact with a counter surface [1]. In order to study tribological behaviours of press hardening, Geiger et al. [2] established a numerical model of cup deep drawing process to use Siebel's equation to calculate the friction coefficient in a forming process. The decreases in the coefficient of friction with increases in temperature were attributed to plastic softening of the blank material. Nevertheless, an examination of tribological behaviours in the press hardening experiment is a complicated process 
because either a wear mechanism or several mechanisms lead to continuous removal of material from the contacting surfaces, and thus, the accumulated wear debris increases the friction force. In order to simplify the mechanical characteristics of a forming operation, researchers designed different laboratory test set-ups. Okonkwo et al. [3] conducted ball-on-disc tests to study tribological behaviours in a cold forming process by considering temperature effects. The tests were performed at elevated temperatures between ambient temperature and $150{ }^{\circ} \mathrm{C}$ to simulate the increase in temperature due to friction work during the sliding process. The observations indicated that higher temperatures decreased the adhesion of the ball material to the tool steel (disc), and increased disc material was removed due to ploughing and spalling. The amount of the transferred material could explain the relatively low friction coefficients that were observed at ambient and $50{ }^{\circ} \mathrm{C}$ as well as high friction coefficients that were observed at $100{ }^{\circ} \mathrm{C}$ and $150{ }^{\circ} \mathrm{C}$. Mozgovoy et al. [4] conducted a high-temperature reciprocating test in which the oscillating sliding on the disc was performed by a pin with a flattened surface and observed that lower and more stable friction coefficients occurred at higher temperatures due to the formation of protective and compacted layers of wear debris that prevented the sliding track from metal-to-metal contact and caused the wear rate of the disc to decrease above $200^{\circ} \mathrm{C}$. However, simplified laboratory tests, such as ball-on-disc tests and reciprocating tests, do not simulate press hardening processes. This is because the sliding process repeatedly occurred in at least one of the counter parts in which friction heat caused mechanical changes in the specimens and the contacting surface could change at the microcosm level including plastic hardening and the formation and removal of oxidized layers. Furthermore, tribological behaviours, such as friction behaviour and material transfer, could differ from a tribosystem to another because tribological behaviours involve system parameters instead of material properties and are affected by every small change in the set-up of the tribosystem, process parameters, chemical constituents, and surrounding environments.

In order to obtain a deeper understanding of tribological behaviours under press hardening conditions, contact conditions of a press hardening experiment were studied by means of FE simulations of a production test line. Typically variational contact conditions with respect to pressure and sliding velocity served as a base to determine test parameters for a tribological test. The tribological test mimics the sliding process of press hardening as closely as possible, and this results in a possible correlation between the test parameters and the consequent friction coefficients and mass losses. The tribological study in the present study was confined by friction behaviour and mass loss of tool steels, which characterized the mechanism by which two solids slid and the consequent material transfer that occurred. A future study will focus on wear mechanisms and topography analysis of the worn surface.

\section{Contact Conditions in a Press Hardening Experiment}

\subsection{Set-up of the Press Hardening Experiment}

In order to study tribological behaviours of press hardening in laboratory environments, a press hardening experiment representing typical press hardening processes in automotive industries was performed in a production test line. The set-up of the press hardening experiment and the geometrical measurements are shown in Fig. 1. The initial temperature of the blank was set at $930{ }^{\circ} \mathrm{C}$, and this was followed by a cooling process for $11 \mathrm{~s}$ as the heated blank was transferred from the furnace to the die. Given cooling by an effective heat transfer coefficient of $120 \mathrm{Wm}^{-2} \mathrm{~K}^{-1}$, the temperature in the blank decreased to $763{ }^{\circ} \mathrm{C}$ when the stamping tools began to form. In the drawing process, the punch loaded by force moved down with the holders. However, a gap of $2.6 \mathrm{~mm}$ was maintained until the end of the drawing process. Following the drawing process, the water in the tool channels was cooled down the formed blank until the martensite phase was reached during $9 \mathrm{~s}$. The tools were composed of hot work tool steels, and the blank was made of $22 \mathrm{MnB} 5$ steel. The material properties used in the press hardening experiment are presented in Table 1 based on [4].

\subsection{Simulation of the Press Hardening Experiment}

A numerical model of the press hardening experiment using a commercial FE software termed as LS-Dyna, which consisted of 140,101 nodes, 6857 shells, and 125,160 solid elements, was defined on a quarter of the actual geometry due to symmetry. The blank was modelled by four-node Belytschko-Tsay shell elements of $2 \mathrm{~mm}$ each with 5 integration points through the initial thickness of $1.6 \mathrm{~mm}$. The smallest element length defined for the tools in the contact surface corresponded to $1 \mathrm{~mm}$. However, it increased until $10 \mathrm{~mm}$ in the bulk due to high computational cost. The thermal expansion of boron-manganese steels due to the heating process was simulated with assumed volume fractions of $80 \%$ ferrite and $20 \%$ pearlite, and this expanded the thickness to $1.618 \mathrm{~mm}$. Following the heating process, the numerical model commenced with a cooling process of the blank mimicking the transfer process, and this was followed by a drawing process and a 


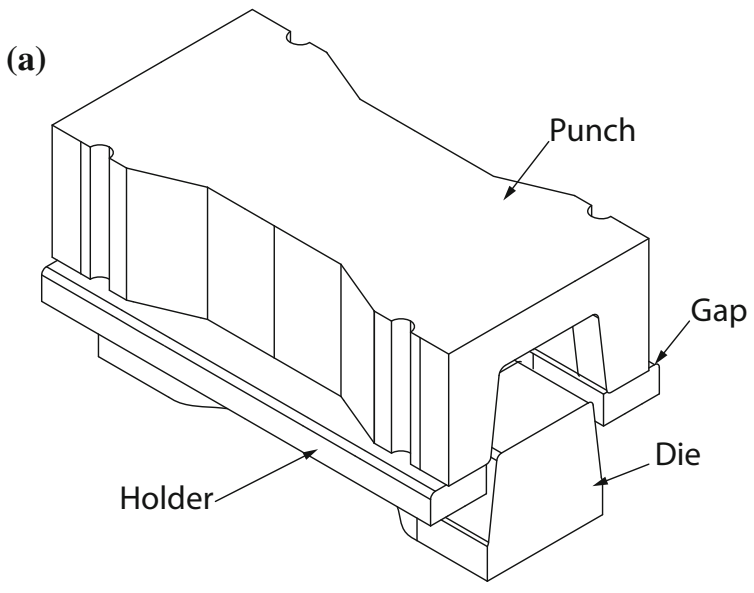

(b)

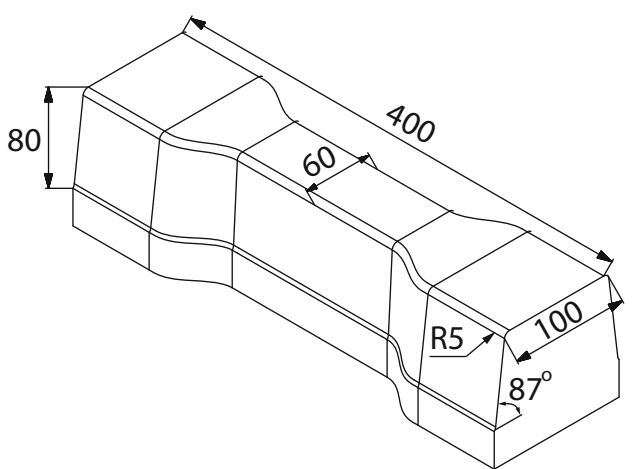

(c)

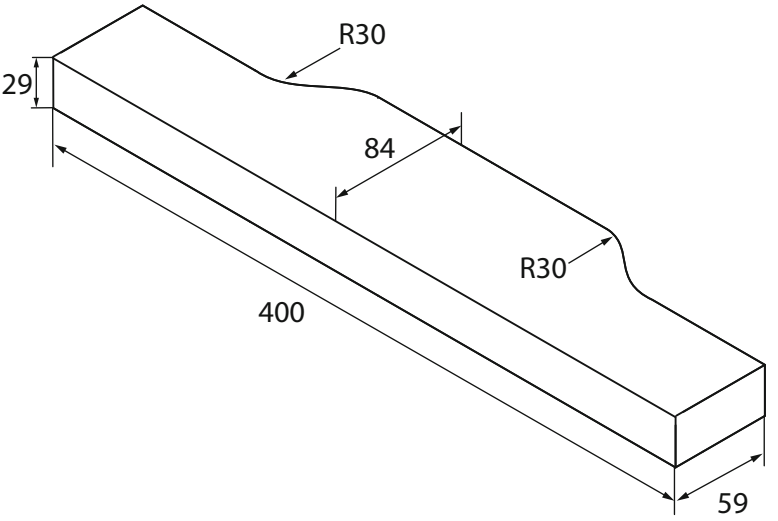

(d)

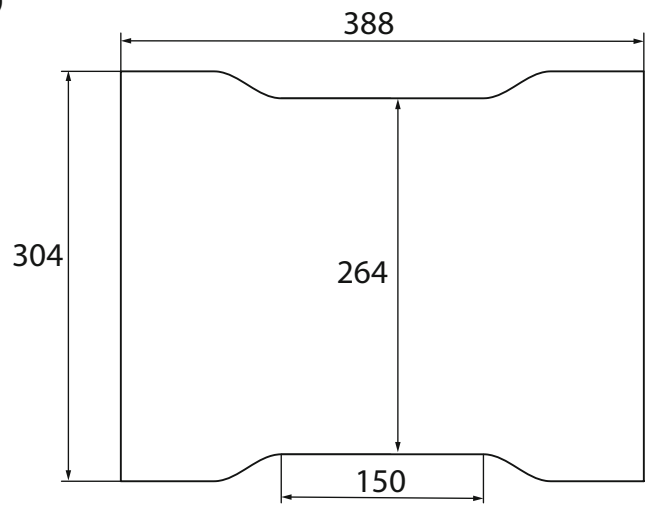

Fig. 1 Illustration of the press hardening model; all dimensions are given in millimetres

cooling down process. A thermoelastic-plastic constitutive model based on the von Mises yield criterion with associated plastic flow that described the phase transformation and deformation behaviour of the blank was developed by Åkerström [5] and Åkerström et al. [6]. This model was implemented in LS-Dyna, and the material properties of the boron-manganese steel at elevated temperatures could be extracted based on a previous study by Åkerström and Oldenburg [7]. The stamping tools corresponded to rigid bodies, and their initial and constant boundary temperature corresponded to $40{ }^{\circ} \mathrm{C}$. A constant heat transfer coefficient of $6000 \mathrm{Wm}^{-2} \mathrm{~K}^{-1}$ was used for the uncoated tool-blank interface, which coefficient was extracted from the work on a validated austenite decomposition model presented in [8]. The heat capacity was assumed as the same for the X40CrMoV5-1 tool material (see [9]), and the thermal conductivity of the tools was provided by the steel supplier as shown in Table 2. The static and dynamic friction coefficients for forming the uncoated material were both assumed as 0.56 . The present model was analysed by an explicit solver with a real drawing velocity corresponding to $100 \mathrm{~mm} / \mathrm{s}$ without thermal scaling although the heating and cooling processes were speeded up by 100 times each.

In the present study, the thickness of the formed blank was used to validate the numerical model of the press hardening experiment. As shown in Fig. 2, two regions (dash line) were measured on the formed blank based on the $\mathrm{FE}$ simulation in which $\mathrm{Z} 1$ represented the mild thickness change region and region $\mathrm{Z} 2$ experienced a significant change in thickness. The thickness measurement was performed by a micrometre and was averaged across 20 repetitions in each measured position. As shown in Fig. 3, the tendency of the calculated thickness was consistent with the measured results.

\subsection{Presentation of Contact Conditions}

The presentation of the contact conditions could serve as a basis for designing a simplified test aimed at reproducing the tribological behaviours of press hardening in laboratory environments. The contact conditions occurring in the stamping tools were statistically analysed as shown in Table 3. The contact force assembling the reflective forces on the slave and master sides produced the nodal pressure as a quotient of the contact force and the sum of fragmentary areas of the neighbouring segments. According to Pereira et al. [10], transient pressure could reach an extremely high value that exceeds $1000 \mathrm{MPa}$. However, the extremely high value of contact pressure was not 
Table 1 Alloying compositions (wt\%), initial hardness, and surface roughness

\begin{tabular}{lllllllllllll}
\hline Material & $\mathrm{C}$ & $\mathrm{Si}$ & $\mathrm{Mn}$ & $\mathrm{P}$ & $\mathrm{S}$ & $\mathrm{Cr}$ & $\mathrm{Mo}$ & $\mathrm{V}$ & $\mathrm{Ni}$ & $\mathrm{B}$ & $\mathrm{HV} 0.5$ & $\mathrm{Ra} / \mathrm{um}$ \\
\hline 22MnB5 & $0.20-0.25$ & $0.20-0.35$ & $1.0-1.3$ & Max. 0.03 & Max. 0.01 & $0.14-0.26$ & - & - & - & 0.005 & $201 \pm 3$ & $1.16 \pm 0.16$ \\
Tool steel & 0.32 & $0.6-1.1$ & 0.8 & Max. 0.001 & Max. 0.003 & 1.35 & 0.8 & 0.14 & Max. 1 & - & $458 \pm 6$ & $0.13 \pm 0.01$ \\
\hline
\end{tabular}

Table 2 Thermal parameters for stamping tools

\begin{tabular}{lll}
\hline$T\left({ }^{\circ} \mathrm{C}\right)$ & $C_{p}\left(\mathrm{~J} / \mathrm{Kg}{ }^{\circ} \mathrm{C}\right)$ & $k\left(\mathrm{~W} / \mathrm{m}{ }^{\circ} \mathrm{C}\right)$ \\
\hline 20 & 460 & 34 \\
200 & 460 & 32 \\
800 & 460 & 31 \\
\hline
\end{tabular}

observed in the present study because the hot blank was relatively soft in the press hardening experiment. The high standard deviations of contact pressure indicated that the pressure was unevenly distributed over the tools. The median pressure that occurred in the upper tool corresponded to $28.3 \mathrm{MPa}$, and this implied that most part of the tool experienced the pressure within the range from 20 to $30 \mathrm{MPa}$. The relative distance between the pass-by blank and the tool at each time step accumulated as the sliding distance. The maximum sliding distance that occurred in the upper tool exceeded that obtained in the lower tool by one magnitude level. The sliding velocity corresponded to the value of the relative distance divided by the time step of the explicit solution. Even the transient sliding velocity exceeded the drawing velocity, and most of the velocities measured in the upper tool dropped in magnitude levels from 0.01 to $0.1 \mathrm{~m} / \mathrm{s}$. The mean tool temperatures in the upper tool as well as the lower tool reached approximately $200{ }^{\circ} \mathrm{C}$. The upper tool experienced harsher contact conditions when compared with that of the lower tool. Therefore, the contact conditions that occurred in the upper tool formed the main basis for designing the test programme of the tribological test. Additionally, most of the extreme contact conditions appeared in the observation area within the curved part of the tool radius as shown in
Fig. 4. Figure 5 indicates the extreme contact conditions obtained by the FE simulation with respect to contact pressure, sliding distance, surface temperature, and the temperature in the blank passing by the tools. Most of the sliding process between the blank and the tool resulting in tool wear occurred during the drawing process of the press hardening experiment (0.09-0.9 s). Figure 5a illustrates the contact pressure histories obtained from the nodes that experienced the highest pressures in the upper and lower tools. The oscillation of the pressure that appeared in the upper tool was attributed to the sliding process along the neighbouring elements with stiffness differences. The pressures increased sharply in both tools when the blank began to bend, and this was followed by a relatively stable stage as the upper tool continuously drew on the blank. Following this, the pressures increased drastically as the tools closed. The highest pressure occurred in the end of the drawing, and it may be not significant in the entire drawing process. Figure $5 \mathrm{~b}$ presents the maximum sliding distances that occur in the upper and lower tools. The radius of the upper tool experienced the maximum sliding process since it formed the blank into the targeted shape. Additionally, the lower tool remained stationary during the drawing process, and the sliding process that occurred in it was mainly caused by the deformation of the blank. Based on the implementation of FE simulations, the prediction of the tool surface temperatures and the temperatures in the pass-by blank were obtained by a user-defined subroutine integrated with LS-Dyna. Figure $5 c$ and d illustrates the surface temperatures in the contact interface between the pass-by blank and the tools. The fresh blank continuously slid over the radius of the upper tool, and thus, the temperature in the blank passing by the observation area of the

Fig. 2 An illustration of the measured positions on the formed blank. Left Z1, Z2 illustrate the measuring regions on a quarter of the blank; right P1-P9 correspond to the specific measured positions in each measuring region; all dimensions are in millimetres
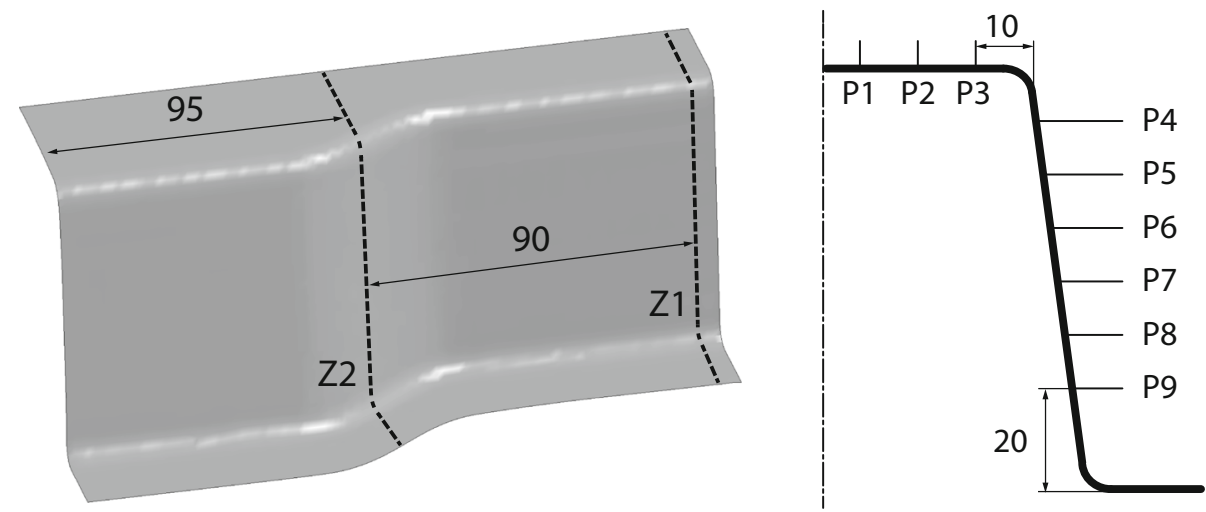


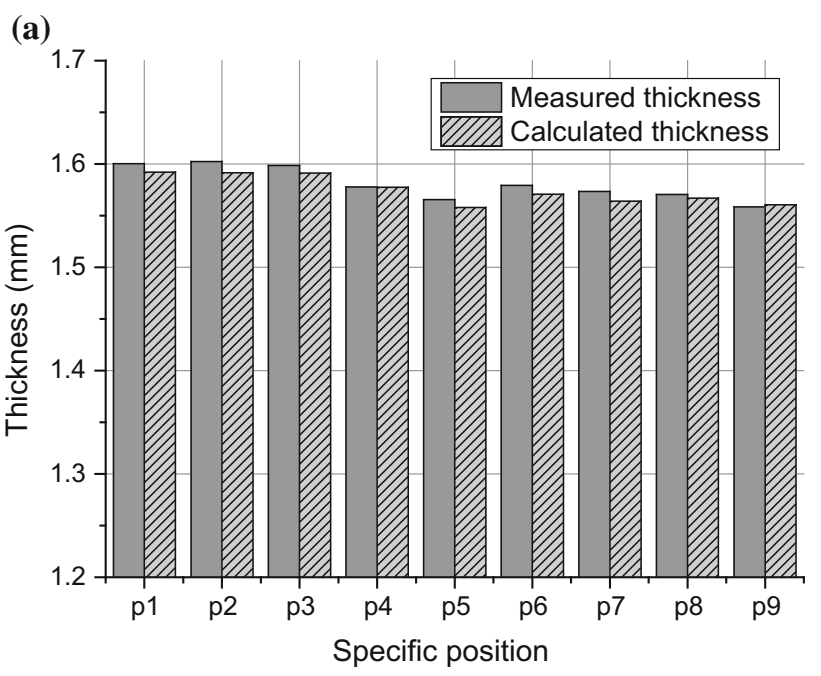

(b)

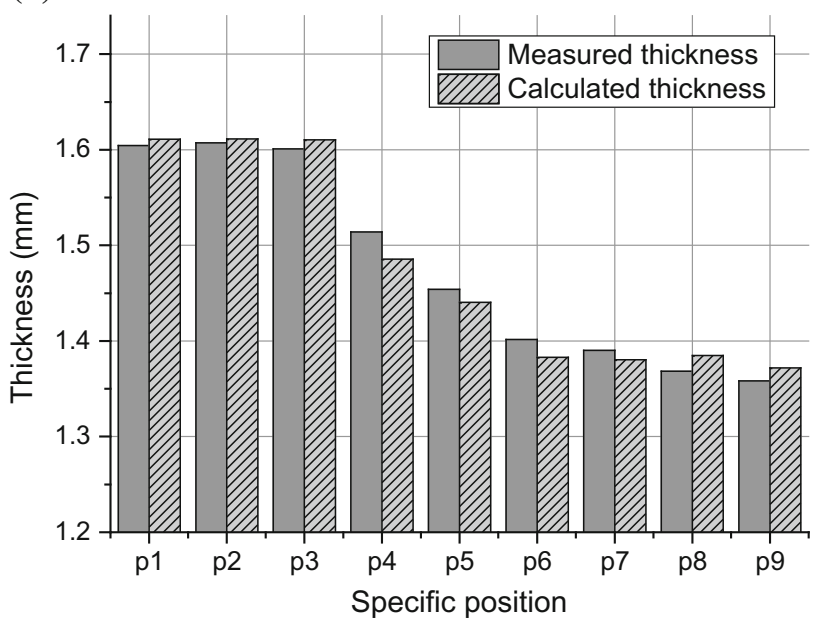

Fig. 3 Comparison of the formed blank thickness between the measured results and calculated results

upper tool exceeded $750{ }^{\circ} \mathrm{C}$. Additionally, the temperature in the observed node in the upper tool continuously increased until $445^{\circ} \mathrm{C}$ due to the combined effect of friction energy accumulation and heat transfer. The decrease in the sliding distance and the increase in stagnation between the lower tool and the hot blank resulted in the increased transfer of heat from the blank to the lower tool. The apparent decrease in temperature in the pass-by blank and the increasing tool temperature are shown in Fig. 5d.

\section{Experimental Conditions}

\subsection{The Set-up of a Tribological Test}

A tribological test that included a pair of tool steel pins sliding on a boron-manganese steel strip was designed to
Table 3 Statistics of the contact conditions

\begin{tabular}{lll}
\hline Tool & Upper tool & Lower tool \\
\hline Max. pressure (MPa) & 214.0 & 109.0 \\
Mean pressure (MPa) & 37.4 & 27.2 \\
Std. deviation pressure (MPa) & 35.7 & 23.4 \\
Max. sliding velocity $(\mathrm{m} / \mathrm{s})$ & 0.14 & 0.11 \\
Mean sliding velocity $(\mathrm{m} / \mathrm{s})$ & 0.077 & 0.0043 \\
Std. deviation velocity $(\mathrm{m} / \mathrm{s})$ & 0.029 & 0.0062 \\
Max. sliding distance $(\mathrm{m})$ & 0.063 & 0.0024 \\
Mean sliding distance $(\mathrm{m})$ & 0.014 & $5.7 \mathrm{E}-4$ \\
Std. deviation distance $(\mathrm{m})$ & 0.015 & $6.1 \mathrm{E}-4$ \\
Max. surface temperature $\left({ }^{\circ} \mathrm{C}\right)$ & 445.0 & 302.0 \\
Mean surface temperature $\left({ }^{\circ} \mathrm{C}\right)$ & 204.5 & 184.7 \\
Std. deviation temperature $\left({ }^{\circ} \mathrm{C}\right)$ & 108.4 & 73.0 \\
Max. pass-by temperature $\left({ }^{\circ} \mathrm{C}\right)$ & 768.0 & 768.0 \\
Mean pass-by temperature $\left({ }^{\circ} \mathrm{C}\right)$ & 674.7 & 656.7 \\
Std. deviation pass-by temperature $\left({ }^{\circ} \mathrm{C}\right)$ & 60.9 & 52.9 \\
\hline
\end{tabular}

study the tribological behaviours with respect to press hardening conditions. The basic configuration of the tribological test is shown in Fig. 6. A pair of tool steel pins was loaded against the strip with a tool steel pin from each side and was mounted in a moving assembly driven by a ball screw. A normal load on the tool steel pins was applied through a pneumatic bellow. In contrast to the flattened surfaces of pins employed in a reciprocating test performed by Mozgovoy et al. [4], each of the two pins in the present study was designed with a spherical tip with a radius of $50 \mathrm{~mm}$. The tip design was adopted to maintain the alignment of test specimens and to reach higher pressures. The vertical set-up of the strip could avoid unexpected scuffing due to the wear debris produced during the sliding process. A pneumatic cylinder that provided pretension kept the strip straight. Furthermore, clamping jaws holding the strip were attached to the strain gauge force transducers to provide friction force measurement during sliding. Prior to the sliding process, the strip was heated to the austenite phase of boron steels via the Joule effect by passing a current through the strip. The typical temperature of the pass-by blank sliding over the upper tool varied around $750{ }^{\circ} \mathrm{C}$ as shown in Fig. 5c. Thus, the test temperature of the strip was set at $750{ }^{\circ} \mathrm{C}$ after the fully austenite phase. The pressure and sliding velocity varied in the stamping tool during the drawing process, and their effects on the tribological behaviours were unclear. Hence, the sliding velocity and pressure served as variables to compose four test condition combinations in the tribological test as shown in Table 4 in which the variables consisted of an upper level and a lower level. The range of the sliding 


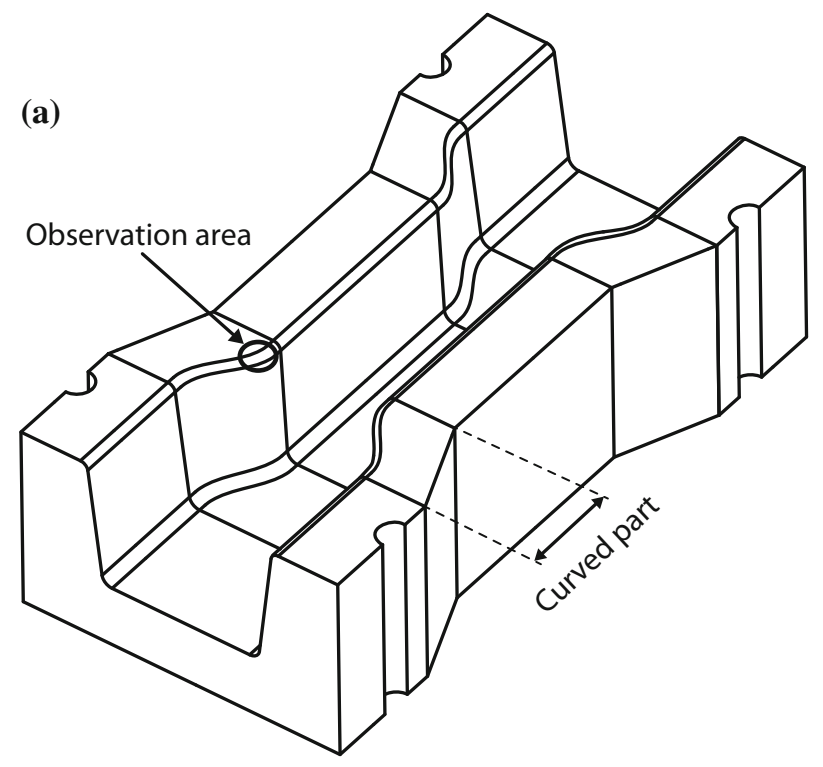

(b)

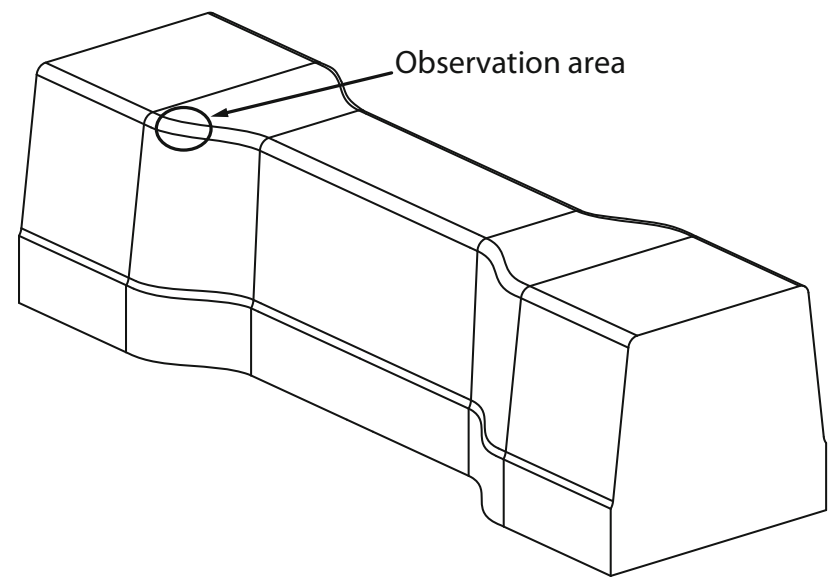

Fig. 4 Illustration of the observation area in the upper tool

velocity in the tribological test covered a reasonable range of sliding velocity that occurred in the upper tool. An extremely high load could tense the hot strip until breakage occurred. Thus, the current loads applied on the pins corresponded to 50 and $150 \mathrm{~N}$. Based on Hertz theory, the maximum pressure of a point contact corresponded to $180 \mathrm{MPa}$ at a low normal load and $270 \mathrm{MPa}$ at a high normal load with a reduced Young's modulus of hot boron steels. The pressure could be reduced to approximately 7.1 MPa at the low applied load and $21.2 \mathrm{MPa}$ at the high applied load with increases in the real contact area. A real contact area of $7.1 \times 10^{-6} \mathrm{~m}^{2}$ was stable under the present test conditions as shown in Fig. 7. The selected sliding distance per strip corresponded to $550 \mathrm{~mm}$ and it approximately reproduced the sliding distance by 9 strokes with respect to the press hardening experiment. When compared with the sliding distance of $50 \mathrm{~mm}$ as obtained in a test performed by Tian et al. [11], the long sliding process on (a)

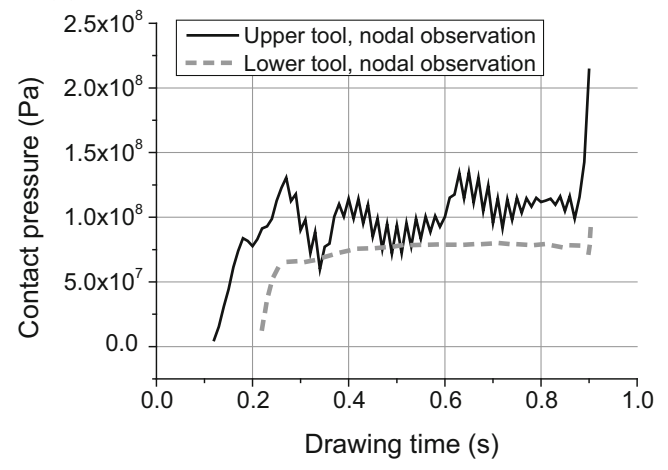

(b)

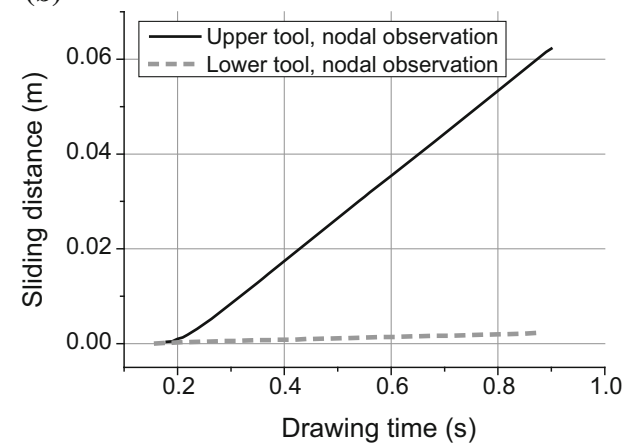

(c)

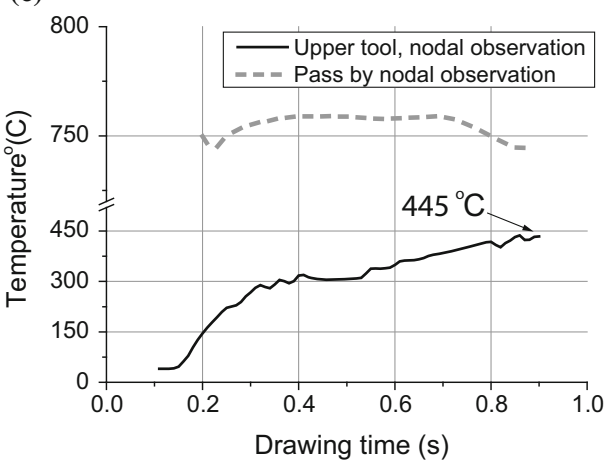

(d)

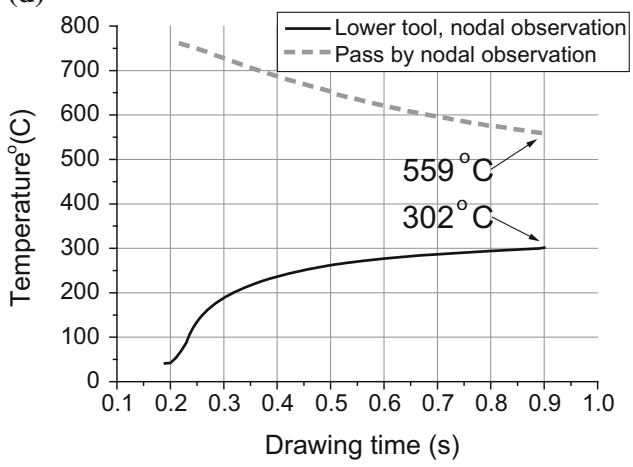

Fig. 5 Illustrations of the extreme contact conditions in press hardening experiment

each strip as obtained in the present study could overcome the fluctuations with respect to the tribological behaviours in the initial stage of the present test. Following the sliding process on a strip, an automated pick and place system 
Fig. 6 a Illustration of the tribological test; $\mathbf{b}$ the geometrical measurements of the tribological test; all dimensions are in millimetres (a)

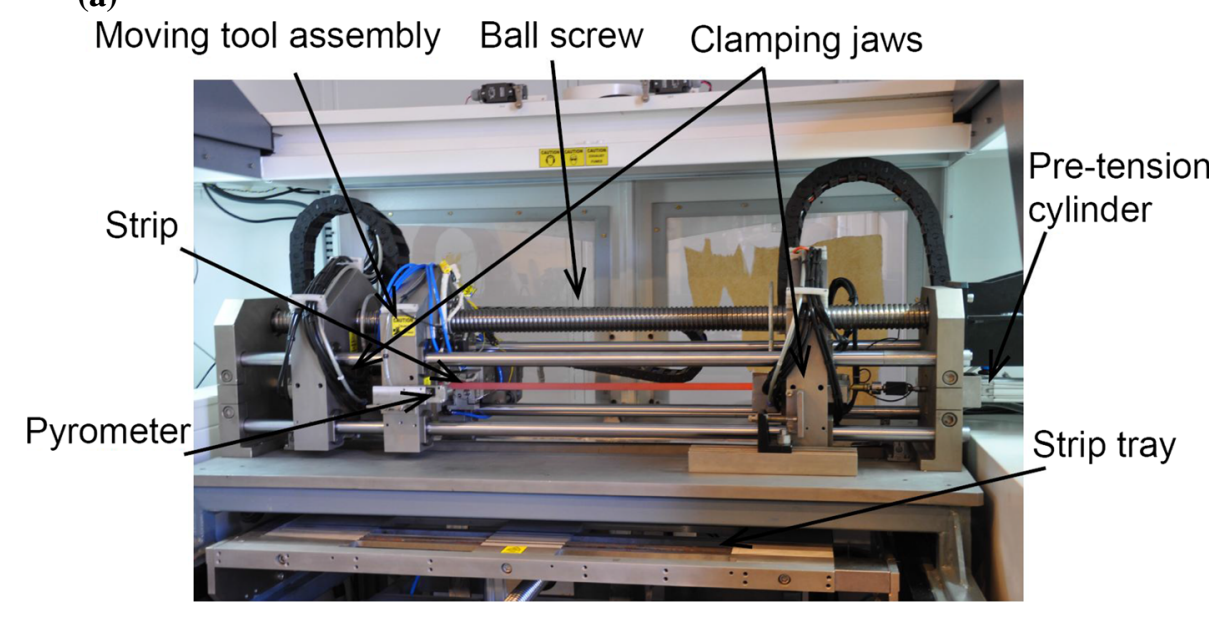

(b)
Table 4 Test parameters in the tribological test

\begin{tabular}{ll}
\hline Load $(\mathrm{N})$ & 50,150 \\
Velocity $(\mathrm{m} / \mathrm{s})$ & $0.01,0.1$ \\
Strip temperature $\left({ }^{\circ} \mathrm{C}\right)$ & 750 \\
Initial pin temperature $\left({ }^{\circ} \mathrm{C}\right)$ & 25 \\
Sliding distance per strip $(\mathrm{m})$ & 0.55 \\
\hline
\end{tabular}

removed the worn strip to a tray and placed a fresh strip in the test position for the next heating-sliding process. The tribological test included ten strips for each parameter combination, and each combination was tested twice. Uncoated 22MnB5 steel with a dimension of $1000 \times 15 \times 1.5 \mathrm{~mm}$ (length $\times$ width $\times$ thickness $)$ was used as the material for the strip, and tool steel with the contact surface polished to a roughness of $0.13 \pm 0.01 \mathrm{um}$ (as shown in Table 1) was used as the pin material. A thermocouple was fixed within $5 \mathrm{~mm}$ of the drilled hole behind the tip surface of the pin. As previously mentioned, strain gauge force transducers provided the friction coefficient via the use of Amonton-Coulomb's law according to Eq. 1 as given below:
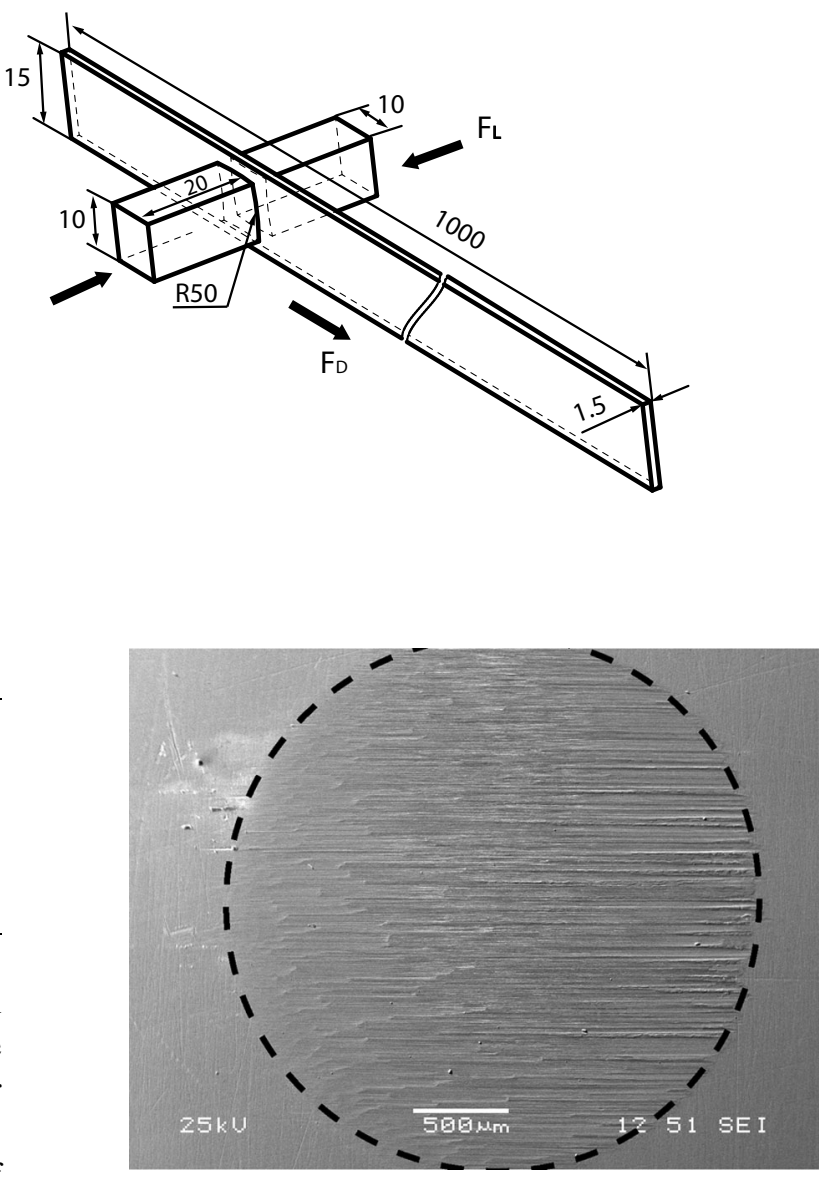

Fig. 7 Scanning electron micrograph of a tool steel pin; the dashed line indicates the estimated contact area

$\mu=\frac{F_{D}-F_{P}}{2 F_{L}}$

where $F_{D}$ represents the drawing force, $F_{P}$ denotes the pretension force, and $F_{L}$ denotes the load applied on the pin. 


\subsection{Simulation of the Tribological Test}

A numerical model of the tribological test provides more contacting information on the tribological behaviours for further study. This numerical model consisted of 247,600 solid elements for the pins and strips, and it was executed with an implicit solution of LS-Dyna. The geometry of the pin with the holder that was used in the FE model is shown in Fig. 8. The constant boundary temperature of the pin bottom was set at $40{ }^{\circ} \mathrm{C}$. The load based on the test programme (see Table 4) was gradually increased on the pin bottom. The aforementioned thermoelastic-plastic material model with material data as given in Table 1 was used for the heated strip, and the thermal data were based on Table 2. The heat transfer coefficient between the hot strip and the pins corresponded to $5000 \mathrm{Wm}^{-2} \mathrm{~K}^{-1}$. The pins were defined as elastic bodies. Furthermore, the coefficient of friction (COF) was based on the average friction coefficient obtained in the tribological test according to different test condition combinations. The normal and tangential interface forces obtained in the FE simulation of the tribological test are shown in Fig. 9 in which the normal interface force based on the penalty contact algorithm was equal to the load. Additionally, the tangential interface force of approximately $80 \mathrm{~N}$ was almost the same as the drawing force of $81 \mathrm{~N}$ in the tribological test (normal load $=150 \mathrm{~N}, \mathrm{COF}=0.54$ ). Furthermore, the contact area of $7.23 \times 10^{-6} \mathrm{~m}^{2}$ obtained in the numerical model

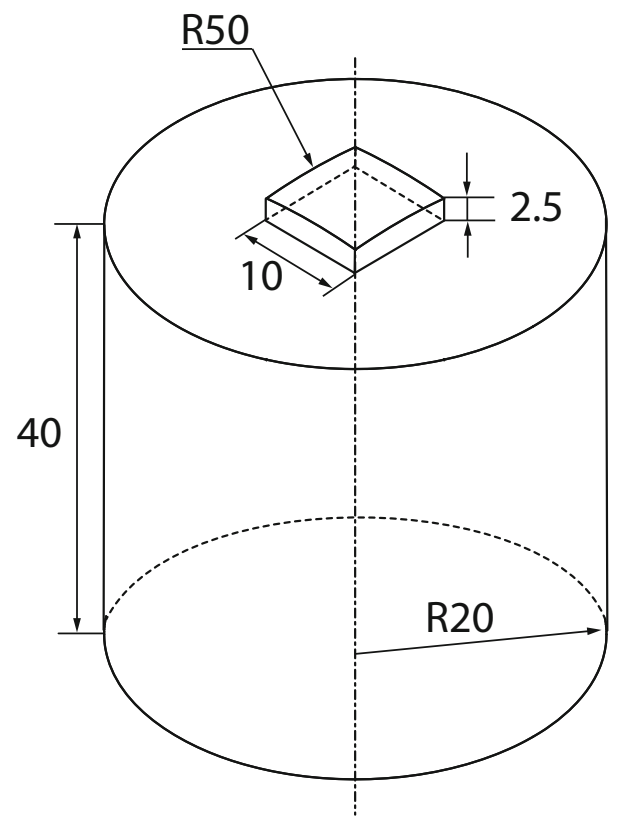

Fig. 8 Geometrical measurements of the pin within a holder used in the FE simulation of the tribological test, all dimensions are in millimetres was close to the estimated area of the pin as shown in Fig. 7.

\section{Experimental Results and Discussion}

In the tribological test, the tool steel pins were mainly exposed to adhesion on the contact surfaces since they were heated through conduction of heat from the uncoated boron-manganese steel strip when the load was applied. This resulted in a higher reactivity of the surfaces. The heat transfer and friction energy accumulation caused the temperature in the pins to increase continuously, and this was similar to the real temperature condition of the stamping tool in press hardening. The pin temperature measured by thermocouples installed $5 \mathrm{~mm}$ during the first strip behind the contact tip was compared with the calculated value obtained in the FE simulation as shown in Fig. 10. The disturbed temperature measurement prior to $2 \mathrm{~s}$ is not presented. The disturbance was caused by delayed temperature responses due to vibrations of the thermocouple within the drilled hole. As observed in Fig. 10, the temperature in the contact tip of the pin increased until $241{ }^{\circ} \mathrm{C}$ as a load corresponding to $50 \mathrm{~N}$ and a velocity of $0.1 \mathrm{~m} / \mathrm{s}$ was applied. This contact temperature after the sliding of $550 \mathrm{~mm}$ exceeded the mean upper tool temperature in the press hardening experiment. The increase in the pin temperature indicated that a long sliding process makes the tribological test different to the press hardening conditions and an interrupted sliding process could be considered in the further study. The temperature analysis in the interface could serve as a reference with respect to which the test conditions of the tribological test could be adjusted to achieve higher reproducibility.

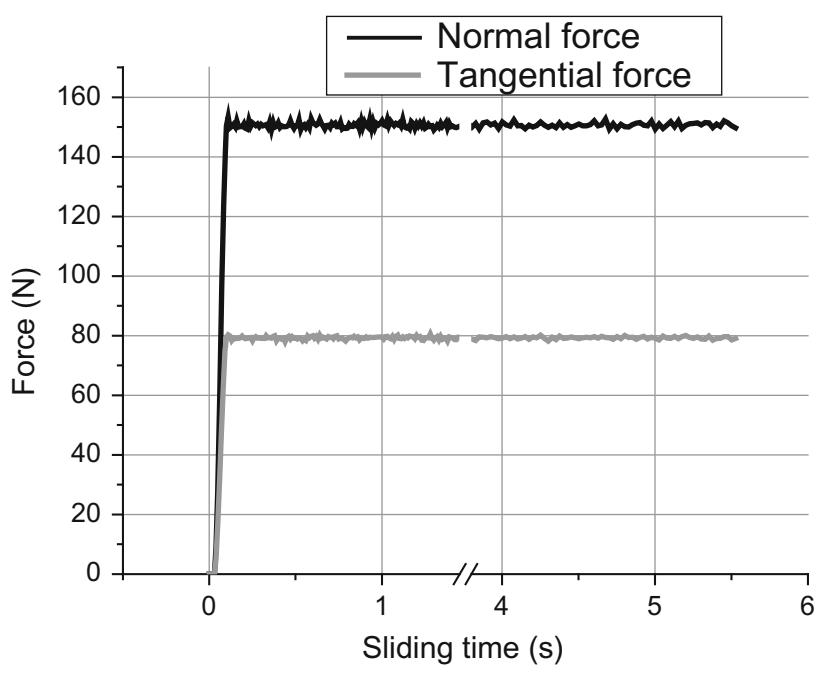

Fig. 9 Normal and tangential interface force in the simulation of the tribological test, load $=150 \mathrm{~N}$, velocity $=0.1 \mathrm{~m} / \mathrm{s}$, and COF $=0.54$ 


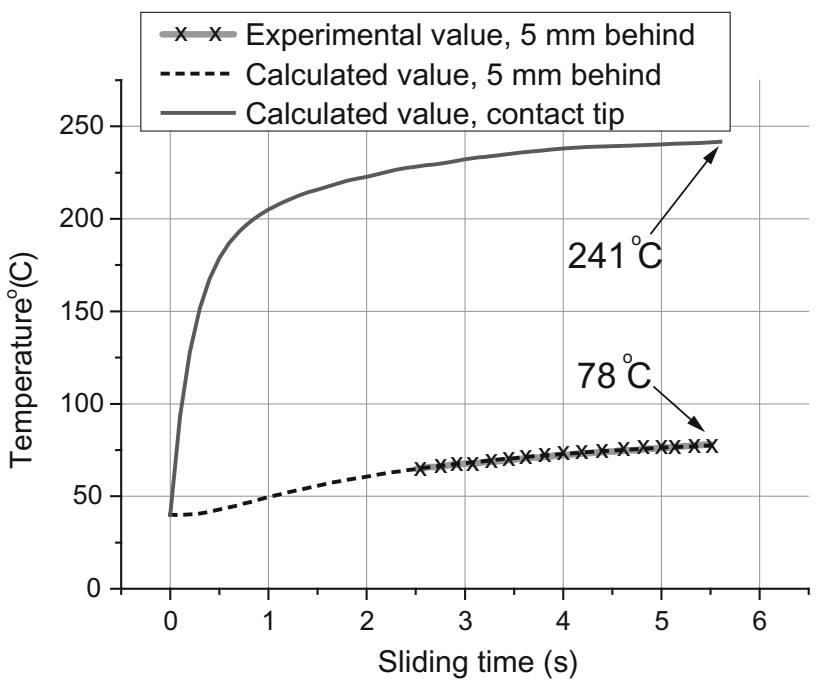

Fig. 10 Temperature measurement $5 \mathrm{~mm}$ behind the contact tip; load $=50 \mathrm{~N}$, velocity $=0.1 \mathrm{~m} / \mathrm{s}$

The tribological test programme proposed in the present study obtained a friction model in which the coefficient of friction $\mu$ exhibited a bilinear relation (see Eq. 2) with respect to the applied pressure and the sliding velocity as observed in Fig. 11a.

$$
\begin{aligned}
\mu(v, P)= & \frac{1}{(0.1-0.01)(21-7)}[0.81(0.1-v)(21-P) \\
& +0.56(v-0.01)(21-P) \\
& +0.76(0.1-v)(P-7) \\
& +0.54(v-0.01)(P-7)]
\end{aligned}
$$

where $v$ represents the sliding velocity in $\mathrm{m} / \mathrm{s}$ and $P$ denotes the normal pressure in MPa. Figure 11b shows the friction coefficients in the present tribological test in which the friction coefficients were averaged in each sequenced strip. A lower load led to higher friction coefficients when compared to those observed in tests with higher loads. Given the same load, a lower sliding velocity resulted in higher friction coefficients since the longer contact time resulted in increased adhesion through the growth of adhesive junctions between the two contacting materials. With respect to the testing conditions in the present study, the influence of the normal load on friction behaviour was much more pronounced when compared to that of the sliding velocity. Yanagida and Azushima [12] reported similar correlations between the friction coefficient and pressure in a hot strip sliding test with respect to a different test programme. However, the strip was heated outside the test position, and thus, the actual strip temperature decreased by approximately $100{ }^{\circ} \mathrm{C}$ during the transferring process. Tian et al. [11] reported consistent correlations between the friction and process parameters with respect to

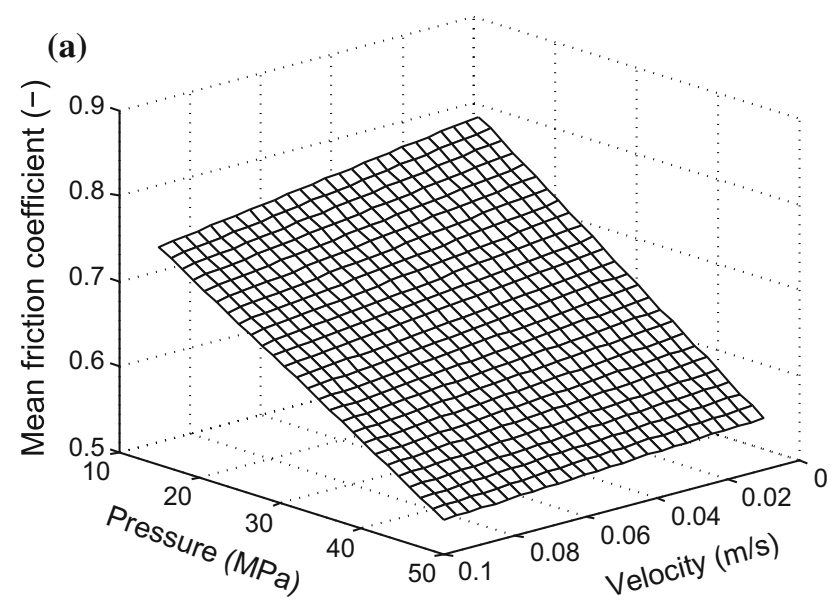

(b)

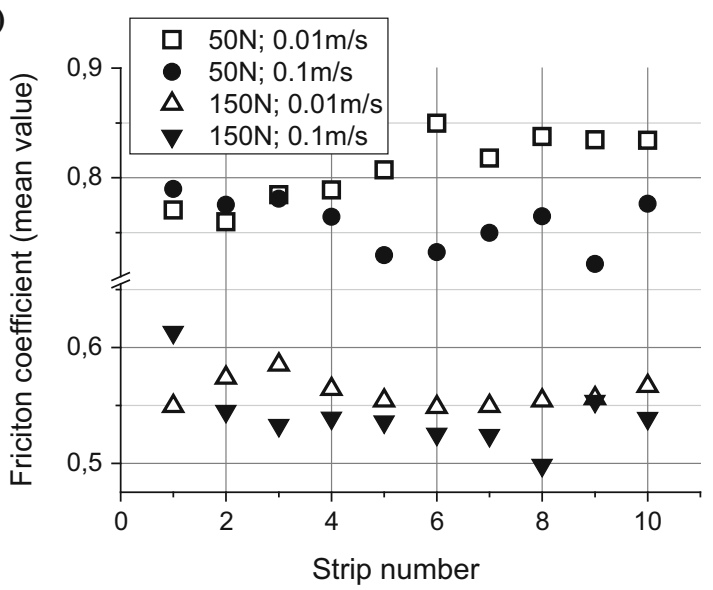

(c)

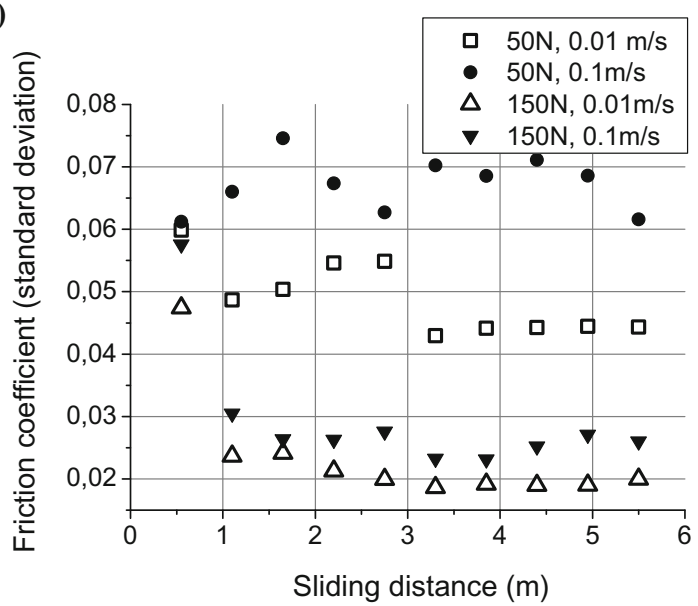

Fig. 11 An Illustration of frictional behaviour in the tribological test

temperature and sliding velocity through a hot strip sliding test with varying process parameters. However, the sliding distance in the study was only $0.05 \mathrm{~m}$, and potentially this short sliding distance was unable to achieve stable responses in the tribological system. Okonkwo et al. [3] revealed that the friction coefficients in a pin-on-disc test 


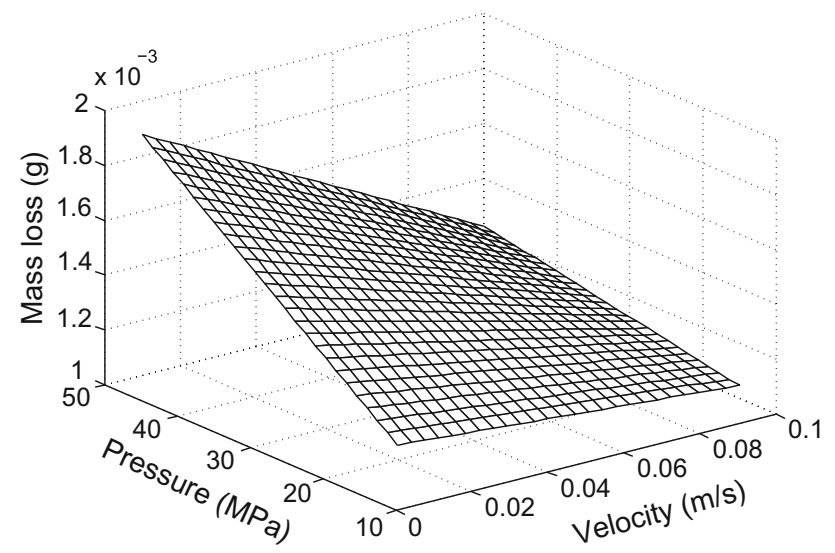

Fig. 12 Mass loss in the tribological test

increased to 0.8 at elevated temperatures until $150{ }^{\circ} \mathrm{C}$. However, the load used in the test was designed to simulate an extremely high pressure that exceeded $1000 \mathrm{MPa}$, which corresponded to the high pressure caused by bending stress and line contact conditions as reported by Pereira et al. [10]. These conditions did not exist in the current study. Given that the friction coefficients fluctuated in certain ranges due to the vibration of the present contact pair, the standard deviations of the friction coefficients as depicted in Fig. 11c indicated that more stable friction coefficients were obtained at higher loads independent of the sliding velocity. This was because the occurring friction forces at low normal loads were close to the sensitivity limit of the strain gauge force transducers. Conversely, the higher load compacted the wear particles and adhesion generated due to the sliding process, and this led to less noise and less fluctuations during the sliding process. However, a lower speed resulted in relatively lower standard deviations of friction coefficients at both loads due to the reduced vibration of the contact pair.

The mass loss of the pins representing the detached wear particles that generated because of the sliding in the present tribological test was measured and averaged following sliding with respect to ten strips. A bilinear relation between the contact conditions and the mass loss was established, and the model was based on the four experimentally tested contact conditions as shown in Fig. 12 and Eq. 3 as follows:

$$
\begin{aligned}
m(v, P)= & \frac{1}{(0.1-0.01)(21-7)}[0.00144(0.1-v)(21-P) \\
& +0.00186(v-0.01)(21-P) \\
& +0.00105(0.1-v)(P-7) \\
& +0.00126(v-0.01)(P-7)][g]
\end{aligned}
$$

where $v$ denotes the sliding velocity in $\mathrm{m} / \mathrm{s}$ and $P$ denotes normal pressure in $\mathrm{MPa}$. Under the same velocity, a higher pressure led to increased mass loss. When the most severe mass loss was observed, the lowest corresponding standard deviation of the friction coefficient was observed. Furthermore, the least mass loss occurred at the highest standard deviation of friction coefficient. This implied that more stable friction behaviour resulted in increased mass loss of the tool steel specimens.

\section{Conclusions}

In the study, the contact conditions of a press hardening experiment were examined to design a simplified test to reproduce the press hardening conditions. A tribological test with a dedicated test programme was developed in which the test programme including the variational process conditions mimicked typical variational contact conditions in press hardening. The results were compared with other set-ups of laboratory, and the findings emphasized that frictional behaviour and mass loss corresponded to system dependent parameters that resulted in differences across different sets of working conditions. Based on the set-up of the tribological test in the study, the correlations between tribological behaviours and process parameters in press hardening were presented and can be used to optimize press hardening processes. Furthermore, the tribological test equipment may be used to study the effect of lubrication on the forming process. The improved space for higher reproducibility was illustrated by the FE simulation of the tribological test, and this revealed that the contacting temperature in the tool steel pin experienced a considerable increase during the sliding process.

Acknowledgements This study was funded by the Swedish Governmental Agency for Innovation Systems, VINNOVA, and the FFI-Sustainable Production Technology programme. The authors gratefully acknowledge the supply of tool material by SSAB EMEA $\mathrm{AB}$ in Öxelosund, Sweden, and the supply of blank material and specimen preparation by Gestamp HardTech $\mathrm{AB}$ in Luleå Sweden.

Open Access This article is distributed under the terms of the Creative Commons Attribution 4.0 International License (http://crea tivecommons.org/licenses/by/4.0/), which permits unrestricted use, distribution, and reproduction in any medium, provided you give appropriate credit to the original author(s) and the source, provide a link to the Creative Commons license, and indicate if changes were made.

\section{References}

1. Bhushan, B.: Modern Tribology Handbook, Two Volume Set. CRC Press, Boca Raton (2000)

2. Geiger, M., Merklein, M., Lechler, J.: Determination of tribological conditions within hot stamping. Prod. Eng. Res. Dev. 2, 269-276 (2008)

3. Okonkwo, P.C., Kelly, G., Rolfe, B.F., Pereira, M.O.: The effect of temperature on sliding wear of steel-tool steel pairs. Wear 282, 22-30 (2012) 
4. Mozgovoy, S., Hardell, J., Deng, L., Oldenburg, M., Prakash, B.: Effect of temperature on friction and wear of prehardened tool steel during sliding against 22MnB5 steel. Tribology 8, 65-73 (2014)

5. Åkerström, P.: Modelling and simulation of hot stamping. Doctoral Thesis, Department of Applied Physics and Mechanical Engineering, Luleå University of Technology, Luleå (2006)

6. Åkerström, P., Bergman, G., Oldenburg, M.: Numerical implementation of a constitutive model for simulation of hot stamping. Model. Simul. Mater. Sci. Eng. 15, 105-119 (2007)

7. Åkerström, P., Oldenburg, M.: Numerical simulation of a thermomechanical sheet metal forming experiment. In: Proceedings of Numisheet 2008, the 7th International Conference and Workshop on Numerical Simulation of 3D Sheet Metal Forming Processes, September 1-5 2008, Interlaken, pp. 569-574 (2008)
8. Åkerström, P., Oldenburg, M.: Austenite decomposition during press hardening of a boron steel-computer simulation and test. J. Mater. Process. Technol. 174, 399-406 (2006)

9. Bergman, G.: Modelling and simulation of simultaneous forming and quenching. Doctoral Thesis, Luleå University of Technology (1999)

10. Pereira, M.P., Duncan, J.L., Yan, W.Y., Rolfe, B.F.: Contact pressure evolution at the die radius in sheet metal stamping. J. Mater. Process. Technol. 209, 3532-3541 (2009)

11. Tian, X.W., Zhang, Y.S., Li, J.: Investigation on tribological behavior of advanced high strength steels: influence of hot stamping process parameters. Tribol. Lett. 45, 489-495 (2012)

12. Yanagida, A., Azushima, A.: Evaluation of coefficients of friction in hot stamping by hot flat drawing test. CIRP Ann. Manuf. Technol. 58, 247-250 (2009) 